\title{
Cardioprotective Effect of Endogenous Pituitary Adenylate Cyclase-Activating Polypeptide on Doxorubicin-Induced Cardiomyopathy in Mice
}

\author{
Hiroyoshi Mori, MD***; Tomoya Nakamachi, PhD**,†; Hirokazu Ohtaki, PhD**; Sachiko Yofu**; \\ Atsushi Sato, MD**; Kimi Endo, MD**; Yoshitaka Iso, MD*; Hiroshi Suzuki, MD*; \\ Youichi Takeyama, MD*; Norihito Shintani, $\mathrm{PhD}^{\dagger+}$; Hitoshi Hashimoto, $\mathrm{PhD}^{\dagger+}$; \\ Akemichi Baba, $\mathrm{PhD}^{\dagger \dagger}$; Seiji Shioda, $\mathrm{PhD}^{* *}$
}

\begin{abstract}
Background: Pituitary adenylate cyclase-activating polypeptide (PACAP) is known as a cytoprotective polypeptide. PACAP and its receptors are expressed in the heart, but it is unclear whether PACAP exerts its protective effect on the myocardium in vivo. The aim of the present study was to investigate whether endogenous PACAP has a cardioprotective effect on Doxorubicin (Dox)-induced cardiomyopathy.

Methods and Results: Dox was intraperitoneally injected to induce cardiomyopathy in wild type (WT) and PACAP knockout (ie, PACAP+/- and PACAP-/-) mice. The survival rates up to 15 days of PACAP+/- mice and PACAP-/- mice were significantly less than that of WT mice. Cardiac function, measured by echocardiography, was significantly lower in PACAP+/- mice than in WT mice at day 10. Morphological examination of sections of myocardium showed degenerative change and fibrosis in PACAP+/- mice at day 10. Serum reactive oxygen metabolites (a marker of oxidative stress), the number of 8-hydroxy-deoxyguanosine-positive nuclei and TdTmediated dUTP nick end-labeling (TUNEL) positive nuclei in the myocardium were higher in PACAP+/- mice than WT mice. However, continuous subcutaneous administration of PACAP38 was able to prevent the myocardial damage typically caused by Dox injection in PACAP+/-.
\end{abstract}

Conclusions: These results suggest that endogenous PACAP might attenuate Dox-induced myocardial damage and that its mechanism of action is likely to be associated with the reduction of oxidative stress and mediated via anti-apoptotic effects. (Circ J 2010; 74: 1183-1190)

Key Words: Apoptosis; Cardiomyopathy; Heart failure; Oxidative stress; PACAP

$\mathbf{P}$ ituitary adenylate cyclase-activating polypeptide (PACAP) is a regulatory peptide that was first isolated from the ovine hypothalamus. ${ }^{1}$ PACAP exists in 2 amidated forms of either 38 and 27 residues, designated PACAP38 and PACAP27, respectively. ${ }^{2}$ PACAP is a member of the vasoactive intestinal polypeptide (VIP)/secretin/ growth hormone releasing hormone family of peptides, and its amino acid sequence shows great similarity to VIP.

PACAP and VIP share 3 kinds of receptors, namely PAC1receptor (PAC1R), and the VPAC1 and VPAC2 receptors. The affinity of PAC1R with PACAP is $100-1,000$ times higher than with VIP, indicating that PAC1R is a relatively selective receptor for PACAP. ${ }^{3}$

PACAP is widely distributed in the brain and peripheral organs in mammals, and reportedly has diverse functions in the endocrine, nervous, gastrointestinal, immune, and cardiovascular systems., ${ }^{4,5}$ PACAP and its receptors have also been identified in mammalian heart. ${ }^{6-11}$ PACAP modulates the excitability of intracardiac neurons ${ }^{6,12,13}$ and has positive inotropic, chronotropic, and dromotoropic effects on cardiomyocyte. ${ }^{14-16}$ PACAP is also a potent vasodilator in various organs, including coronary and pulmonary arteries.4,14,17-20 Moreover, PACAP has been revealed to have cytoprotectant properties. In the central nervous system, a number of papers have reported that PACAP suppresses ischemic neuronal cell death.1,16,21-24 Renal tube and pancreatic beta cells were also protected by PACAP against various stresss. ${ }^{25-28}$ Recently, PACAP has been shown to protect cardiomyocyte in vitro

Received December 23, 2009; revised manuscript received February 8, 2010; accepted February 9, 2010; released online April 6, 2010 Time for primary review: 21 days

*Division of Cardiology, Department of Internal Medicine, Showa University Fujigaoka Hospital, Yokohama, **Department of First Anatomy, Showa University School of Medicine, ${ }^{\dagger}$ Center for Biotechnology, Showa University, Tokyo and ${ }^{\dagger}$ Laboratory of Molecular Neuropharmacology, Graduate School of Pharmaceutical Sciences, Osaka University, Osaka, Japan

Mailing address: Seiji Shioda, PhD, Department of First Anatomy, Showa University School of Medicine, 1-5-8 Hatanodai, Shinagawaku, Tokyo 142-8555, Japan. E-mail: shioda@med.showa-u.ac.jp

ISSN-1346-9843 doi:10.1253/circj.CJ-09-1024

All rights are reserved to the Japanese Circulation Society. For permissions, please e-mail: cj@j-circ.or.jp 
from oxidative or ischemia/reperfusion stress. ${ }^{29-31}$ These reports suggest PACAP holds potential for the treatment of heart failure.

However, to the best of our knowledge, there is no published evidence that endogenous PACAP has any capacity to rescue heart failure. Therefore, the present study was performed to investigate whether endogenous PACAP has any cardioprotective effects in the failing heart, using Doxorubicin (Dox) to induce cardiomyopathy in a mouse model. Dox is one of the most effective anti-neoplastic drugs used in the treatment of hematological cancer, carcinoma and sarcoma, but its dose is often limited because of its marked cardiotoxicity. High-dose Dox treatment induces a chronic form of cardiomyopathy, which is one of the important causes of heart failure. This heart failure model was used in wild-type (WT) and PACAP knockout mice in this study to identify if endogenous PACAP have any cardioprotective capacity.

\section{Methods}

\section{Animals and Treatments}

The PACAP-KO mice were kindly supplied by Dr Akemichi Baba (Osaka University, Osaka, Japan). ${ }^{32}$ The mice were bred and maintained under specific pathogen-free conditions in the animal facility of Showa University. Mice were housed in a facility with a 12-h/12-h light/dark cycle and were given free access to water and standard rodent chow. Male PACAP-KO (PACAP+/-, PACAP-/-) mice and normal WT mice of the same C57BL/6 background at 10-12 weeks age were used. All experimental procedures involving animals were approved by the Institutional Animal Care and Use Committee of Showa University (08121, 09137). Dox HCl (Kyowa Hakko Co Ltd, Tokyo, Japan) was dissolved in saline and administered by single intraperitoneal injection at a dose of $20 \mathrm{mg} / \mathrm{kg}$. Control mice received the same volume injections of saline only. Because PACAP-/- mice showed a high rate of lethality during postnatal weeks, experiments that did not include survival studies were performed only in PACAP+/- and WT mice. ${ }^{32}$ Thus, groups were mainly divided into WT vehicle, PACAP+/- vehicle, WT Dox and PACAP+/- Dox. The number of mice used in survival studies was 37 for WT mice, 29 for PACAP+/- mice and 6 for PACAP-I- mice.

\section{Measurement of Reactive Oxygen Metabolites (ROM)}

Five days after Dox injection, blood samples of right atrium were collected from 5 to 7 mice from each group. Then, serum concentrations of ROM, as a marker of oxidative stress, were measured using a free radical electron evaluator kit (FREE; Health \& Diagnostics, Naples, Italy), performed according to the manufacturer's instructions. Photometric reading was employed to determine the generation of pinkcolored aromatic ROM derivatives. Briefly, serum samples $(20 \mu \mathrm{l})$ were dissolved in acetate buffer $\left(\mathrm{pH} \mathrm{4.8)}\right.$ with $\mathrm{FeCl}_{2}$ at $37^{\circ} \mathrm{C}$. This was then mixed gently and $20 \mu 1$ of choromogenic mixture added, which included an aromatic alkylamine. After incubation for $5 \mathrm{~min}$ at $37^{\circ} \mathrm{C}$, the pink-colored aromatic derivative generated by the presence of ROM was measured at $546 \mathrm{~nm}$. The results were expressed as unit (CARR U), where one CARR U coincided with the oxidative potentials of $0.08 \mathrm{mg} \mathrm{H}_{2} \mathrm{O}_{2} / \mathrm{dl}$. Measurement of ROM in this manner correlates well with the measurement of the generation of free radicals, as assessed by the electron spin resonance method utilized in our previous study. ${ }^{33}$

\section{Echocardiography}

Mice were anesthetized via mask with $2.0 \%$ sevofrane in a mixture of $\mathrm{N}_{2} \mathrm{O}(1 \mathrm{~L} / \mathrm{min})$ and $\mathrm{O}_{2}(2 \mathrm{~L} / \mathrm{min})$ at 10 days after Dox injection. Echocardiograms were then performed with an EUB-5500 ultrasound machine (HITACHI Medical Corp, Tokyo, Japan) equipped with a 7.5-MHz imaging transducer (WT vehicle $n=6$, PACAP + - - vehicle $n=5$, WT Dox $n=12$, PACAP+/- Dox $n=9$ ). The transducer was placed in gentle contact with the mid-precordial area through a transmission medium. The left ventricular internal dimensions at the end of diastole (LVEDD) and at the end of systole (LVESD) were measured digitally on the M-mode tracing. LV fractional shortening (\%FS) was calculated as [(LVEDD-LVESD)/ LVEDD] $\times 100$.

\section{Histological Studies}

Ten days after Dox injection, the mice were euthanized and the heart was isolated and fixed with a $10 \%$ solution of formalin in PBS. Following dehydration, the ventricular tissue at papillary muscle level was embedded in paraffin and serially cut to produce $4-\mu \mathrm{m}$ thick sections. These were stained with either (1) hematoxylin and eosin or (2) Sirius red F3BA $(0.1 \%$ solution in saturated aqueous picric acid; Sigma Aldrich, St. Louis, MO, USA). Fibrosis area/total area (\%) data was obtained from Sirius red stained sections using image analysis software WinROOF (Mitani Shoji, Tokyo, Japan).

\section{Electron Microscopy}

Cardiac specimens taken 10 days after Dox injection were immersion-fixed in phosphate-buffered $2.5 \%$ glutaraldeyde ( $\mathrm{pH} 7.4$ ), post-fixed with $1 \%$ osmium tetroxide, dehydrated through a graded ethanol series and embedded in Epon medium. Ultrathin sections were stained with uranyl acetate and lead citrate and observed in a H-7600 electronic microscope (HITACHI Medical Corp, Tokyo, Japan). Five hearts from each group were examined. Ten pictures were taken of each heart and scored using a scale of qualitative scoring $(0+$, normal; $1+$, early degenerative alterations in some cells; $2+$, advanced degenerative changes; 3 , myofibrillar atrophy, loss of contractile elements; 4+, myofiber degeneration accompanied by myolysis) and quantitative scoring (ie, $0+$, normal; $1+$, involvement of single scattered myofibers; $2+$, involvement of groups of myofibers; $3+$, focal groups; 4+, confluent groups). ${ }^{34,35}$ The average of the qualitative and quantitative score was then used for evaluation. Diameters of 100 myofibrils at the z-disk from each heart were also measured using scion image.

\section{Immunohistochemical Analysis}

Six $-\mu \mathrm{m}$ paraffin sections were de-paraffined and boiled in $10 \mathrm{mmol} / \mathrm{L}$ citrate buffer $(\mathrm{pH} 6.0)$ at $90^{\circ} \mathrm{C}$ for $20 \mathrm{~min}$. Following incubation in $0.3 \% \mathrm{H}_{2} \mathrm{O}_{2}$, the sections were blocked with $5 \%$ normal horse serum for $1 \mathrm{~h}$. Subsequently, the sections were then incubated overnight with the specific primary antibody against 8 -hydrodeoxy-guanosine at $4{ }^{\circ} \mathrm{C}(1: 100,8$ OHdG; JaICA, Shizuoka, Japan). The primary antibodies were detected using biotinylated goat anti-mouse IgG following a 90-min incubation at room temperature. The immunoreactivity was visualized with use of the avidin-biotin complex and the chromogen DAB (all Vector Labs, Burlingame, CA, USA). The specificity of the immunoreaction was tested by incubation in blocking buffer instead of the primary antibodies. Nuclei were counterstained with hematoxylin and 8$\mathrm{OHdG}$ positive nuclei were counted in 10 pictures of 5 hearts from each group. TdT-mediated dUTP nick end-labeling 


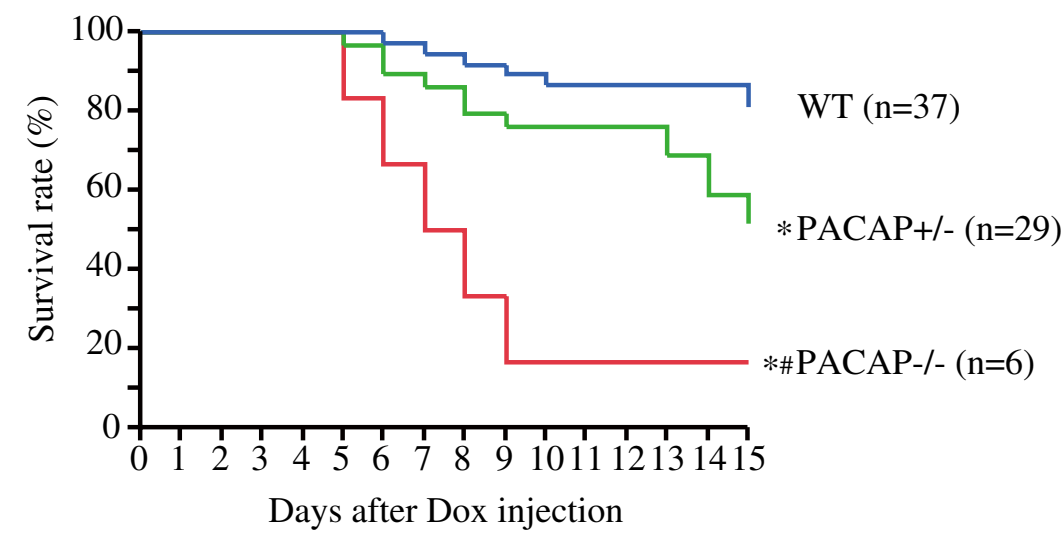

Figure 1. Survival studies. Survival curves after Dox injection in WT and PACAP+/- and PACAP-/- mice. Survival curves were created by KaplanMeier method analysis and compared by log-rank test. Percentages of surviving WT and PACAP+/- and PACAP-/mice were plotted. ${ }^{\star} P<0.05$ compared with WT. \#P<0.05 compared with PACAP+/-. Dox, Doxorubicin; PACAP, pituitary adenylate cyclase-activating polypeptide; WT, wild-type.
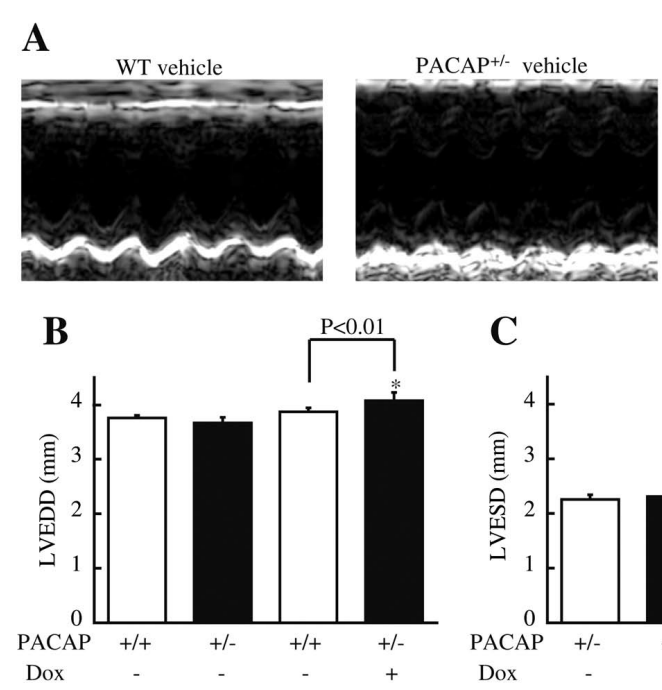

C

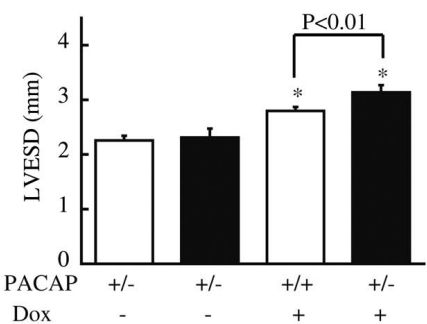

WT Dox

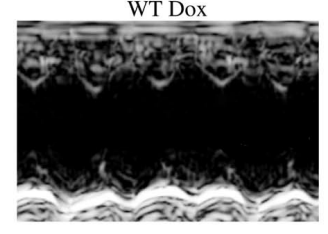

D
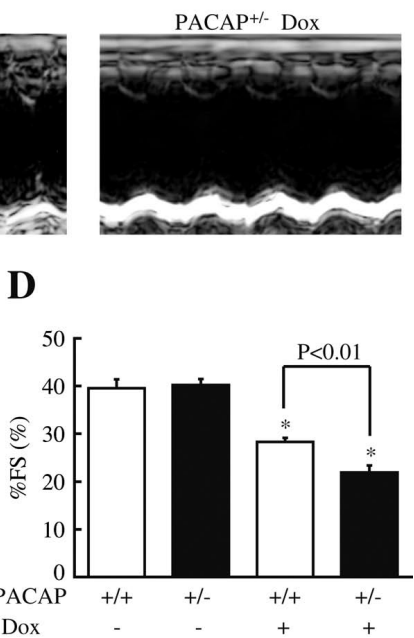

Figure 2. Echocardiography. (A) Representative M-mode echocardiograms of WT and PACAP+/- mice given vehicle or Dox. (B-D) Quantitative data from echocardiographic measurements: B, LVEDD; C, LVESD; and D, \%FS (WT vehicle $n=6, P A C A P+/-$ vehicle $n=5$, WT Dox $n=12$, PACAP+/-Dox $n=9)$. * $P<0.01$ compared with WT vehicle. Dox, Doxorubicin; LVEDD, left ventricular internal dimensions at the end of diastole; LVESD, left ventricular internal dimensions at the end of systole; \%FS, fractional shortening; PACAP, pituitary adenylate cyclase-activating polypeptide; WT, wild-type.

(TUNEL) procedure with a Cardio TACS kit (R\&D Systems, Miineapolis, MN, USA) was also performed according to the manufacturer's instructions. The number of TUNEL positive nuclei per 1 high power field (HPF, $10,000 \mu \mathrm{m}^{2}$ ) was counted in $10 \mathrm{HPF}$ of 5 hearts from each group.

\section{PACAP38 Administraion}

PACAP+/- mice were anesthetized via mask with $2.0 \%$ sevofrane in a mixture of $\mathrm{N}_{2} \mathrm{O}(1 \mathrm{~L} / \mathrm{min})$ and $\mathrm{O}_{2}(2 \mathrm{~L} / \mathrm{min})$. They were allocated to either the PACAP38-administration group $(n=5)$ or vehicle-recipient group $(n=5)$. Then, they were subcutaneously implanted with a mini osmotic pump $(0.25 \mu \mathrm{l} / \mathrm{h}$; Alzet) that was filled with PACAP38 $(64 \mathrm{pmol} / \mu \mathrm{l}$; Peptide Institute, Osaka, Japan) or 0.1\%BSA saline as vehicle, respectively. Thus, they received PACAP38 or BSA saline continuously throughout the experimental period. The concentration of PACAP delivered $(16 \mathrm{pmol} / \mathrm{h})$ was chosen on the basis of our previous in vivo study. ${ }^{22}$ After mini pump implantation, a single intraperitoneal injection of Dox at the dose of $20 \mathrm{mg} / \mathrm{kg}$ was immediately administered in both groups. Ten days after the Dox injection, electron microscopic observations were again performed as described above.

\section{Statistical Analysis}

All values are expressed as mean \pm SD. The significance of differences between groups was evaluated with the TukeyKramer's HSD test, Student's t-test, or 1-way ANOVA followed by a post-hoc procedure (Tukey-Kramer's HSD test). Survival curves after Dox injection were analyzed by the Kaplan-Meier method and compared by a log-rank test. Statistical significance was accepted at a value of $\mathrm{P}<0.05$.

\section{Results}

\section{Survival Studies}

Figure 1 shows the results of survival experiments up to 15 
A
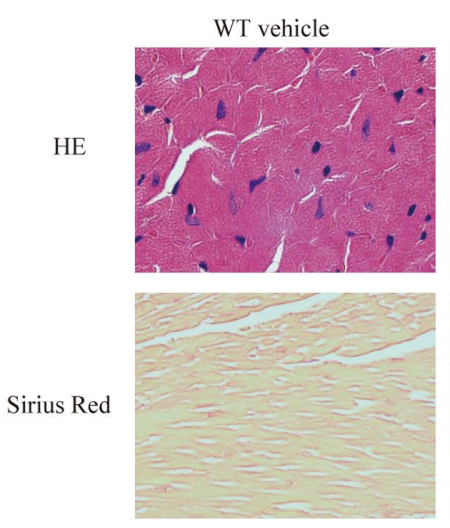

EM

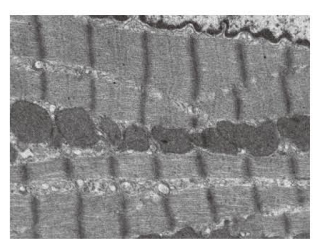

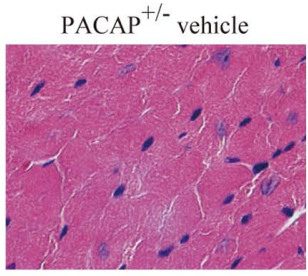
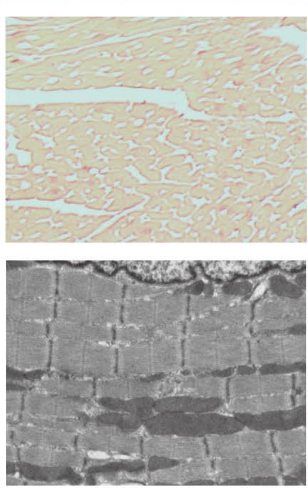
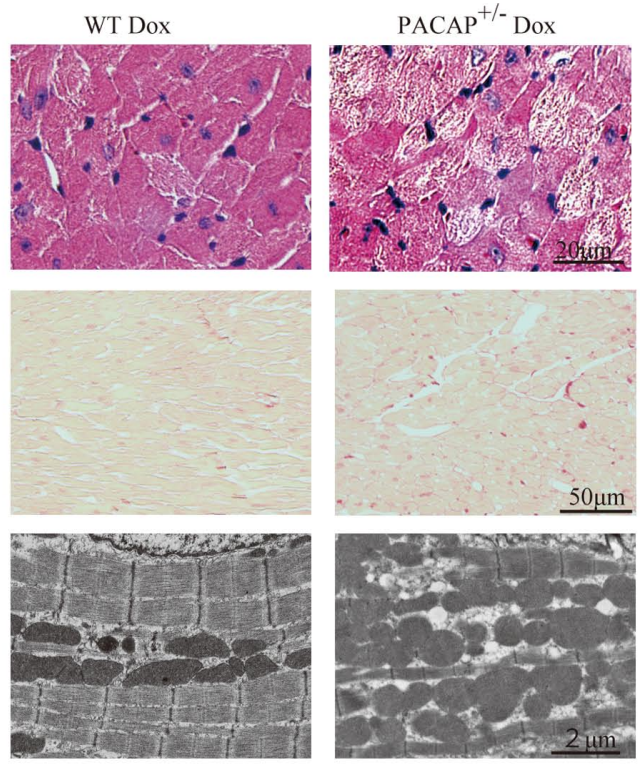

B
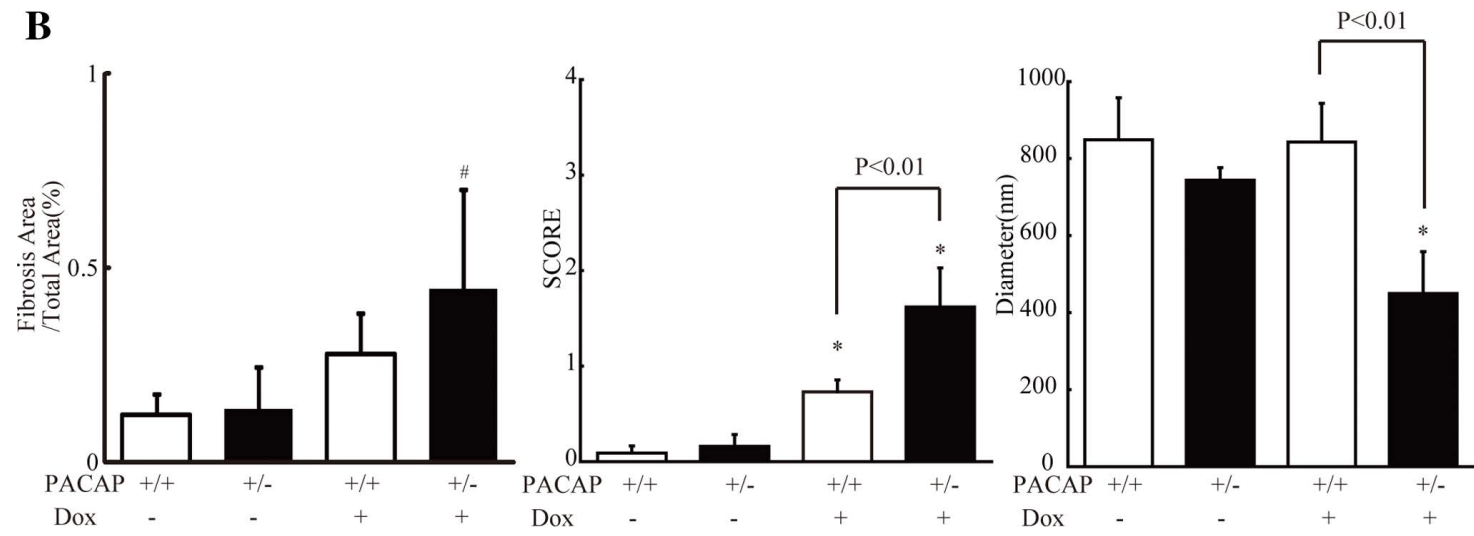

Figure 3. Histological studies. (A) Photomicrograph of histological (Hematoxylin-Eosin [HE], and Sirius-Red [SR]) stained preparations of heart specimens and electron micrographs (EM) of cardiomyoctes. (B) Fibrosis area/total area (\%), electron microscopic scores and myofibrillar diameter measurements at z-disks are shown. Data was obtained from 5 mice in each group. ${ }^{*} \mathrm{P}<0.01$ compared with WT vehicle. ${ }^{\# P}<0.05$ compared with WT vehicle. Dox, Doxorubicin; PACAP, pituitary adenylate cyclase-activating polypeptide; WT, wild-type.

days after Dox injection. Survival rates were compared between PACAP-/-, PACAP+/- and WT mice. PACAP-/and PACAP+/- mice died from 5 days onwards. The survival rate was significantly lower in PACAP-/- mice and PACAP+/- mice compared to WT mice. In addition, the survival rate of PACAP-I- mice was significantly lower than that of PACAP+/- mice.

\section{Echocardiography}

Figure 2A shows representative echocardiograms at 10 days after saline or Dox administration in WT and PACAP+/mice. The LVEDD, LVESD and LVFS showed no significant difference between $\mathrm{WT}$ and PACAP+/- mice that received saline injection. However, the LVEDD and LVESD were markedly increased in PACAP+/- mice compared to WT mice after Dox injection, as shown in Figures 2A, B. Dox caused a reduction of LVFS in both WT mice and PACAP+/mice. The LVFS was also significantly lower in PACAP+/mice compared with WT mice, as shown in Figure 2D. Heart rates after Dox injection were similar between WT and PACAP $+/-$ mice $(424 \pm 72$ vs $443 \pm 47$ beats $/ \mathrm{min})$.

\section{Histological Studies}

The results of morphological examinations performed are shown in Figure 3. The degenerative changes seen after Dox injection were observed in PACAP+/- mice heart sections stained with hematoxylin and eosin (Figure 3A). The extent of cardiac fibrosis was assessed with the Sirius red-stained sections and tend to increase in PACAP+/- mice after Dox injection $(\mathrm{P}=0.20$ Student's t-test, Figure $3 \mathrm{~B})$. No malformations of valves or septal walls were observed within the hearts of WT and PACAP+/- mice (data not shown). No significant difference was observed in the heart-to-body-weight ratios among the various treatment groups (ie, WT vehicle $5.70 \pm 0.72 \mathrm{mg} / \mathrm{g} ;$ PACAP+/- vehicle $6.29 \pm 0.55 \mathrm{mg} / \mathrm{g} ; \mathrm{WT}$ Dox $5.63 \pm 0.51 \mathrm{mg} / \mathrm{g}$; PACAP+/- Dox $6.11 \pm 0.26 \mathrm{mg} / \mathrm{g}$ ).

The presence of Dox-induced degenerative changes in cardiomyocytes was confirmed by electron microscopy exami- 
nation (Figure 3A). Ultrastructural abnormalities such as myofibrillar derangement and disruption and enlargement of subcellular organelles, was frequently observed in PACAP+/mice compared to WT mice after Dox injection (Figure 3A). Moreover, myofibrillar diameter at the z-disk was significantly shorter, and electron microscopic score significantly increased, in PACAP+/- mice (Figure 3B). These degenerative changes were not observed in WT and PACAP+/- mice that received saline injection.

\section{Evidence of Oxidative Stress in Serum and Heart}

The concentrations of ROM, as an index of oxidative stress, in serum were measured 5 days after injection. The serum concentrations of ROM after Dox injection were significantly higher in PACAP+/- (243 \pm 40 CARR U) than WT mice (169 53 CARR U) (Figure 4). There was no significant difference in the level of ROM between WT (114 5 CARR U) and PACAP+/- mice (96 \pm 7 CARR U) injected with saline.

Oxidative stress in the myocardium was evaluated by 8-OHdG immunostaining, a marker for oxidative stress of nucleic acids. Ten days after Dox injection, 8-OHdG-positive nuclei were observed in cardiomyocytes and were significantly increased in number in PACAP+/- compared to WT mice (Figures 5A, B). DNA damage was also visualized with

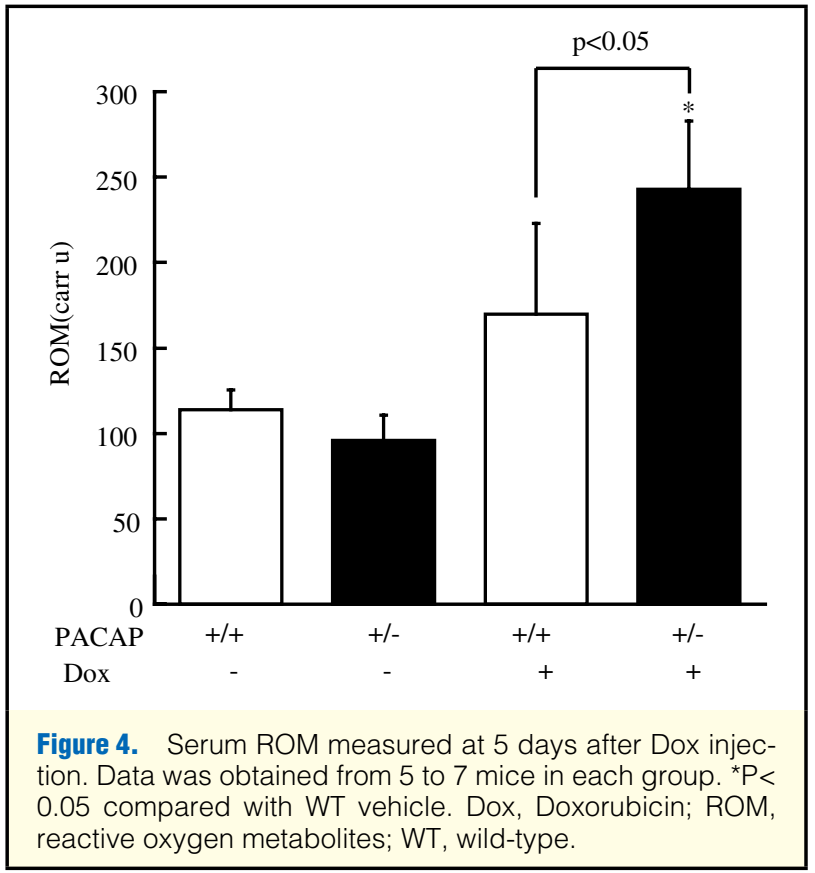

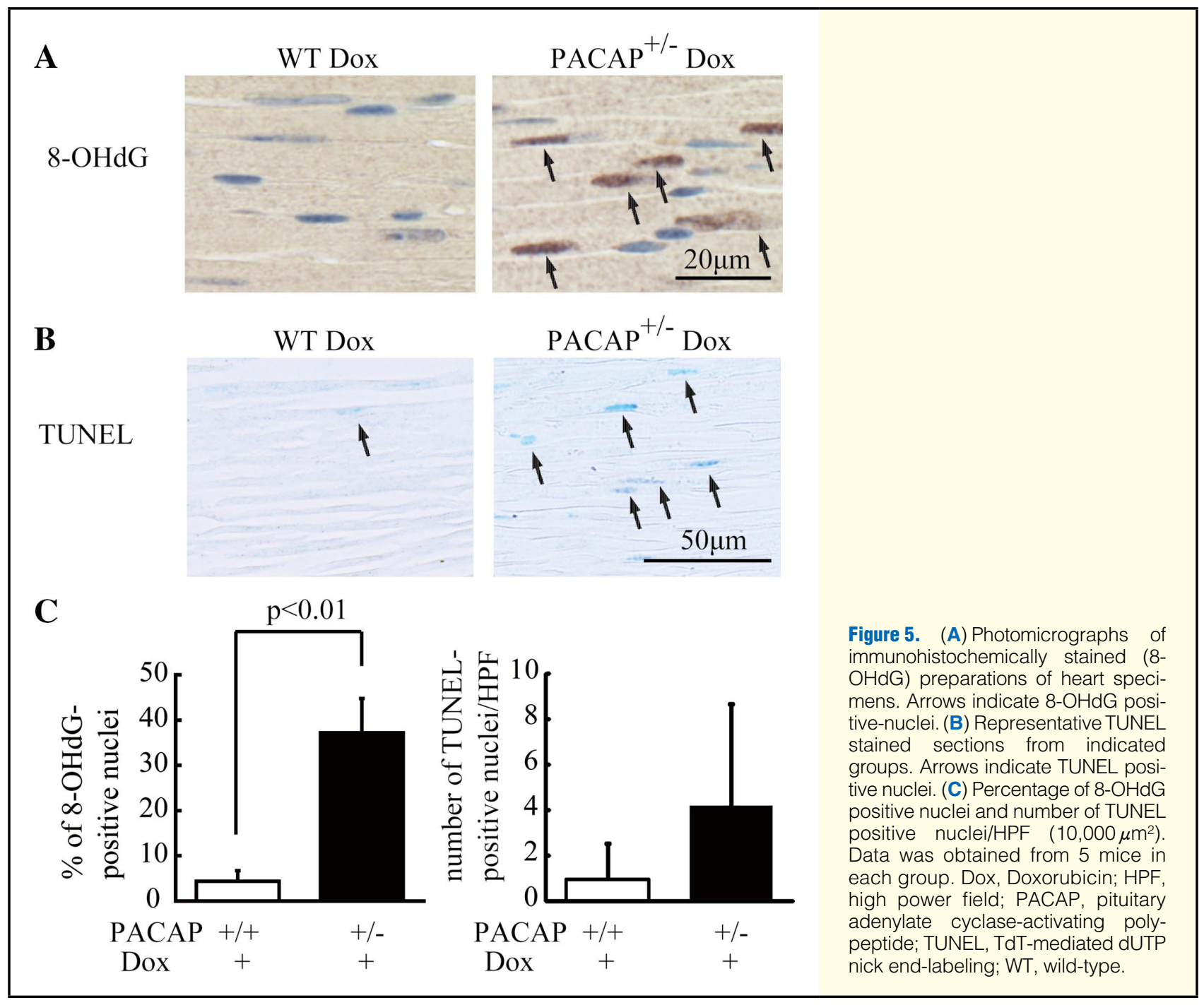




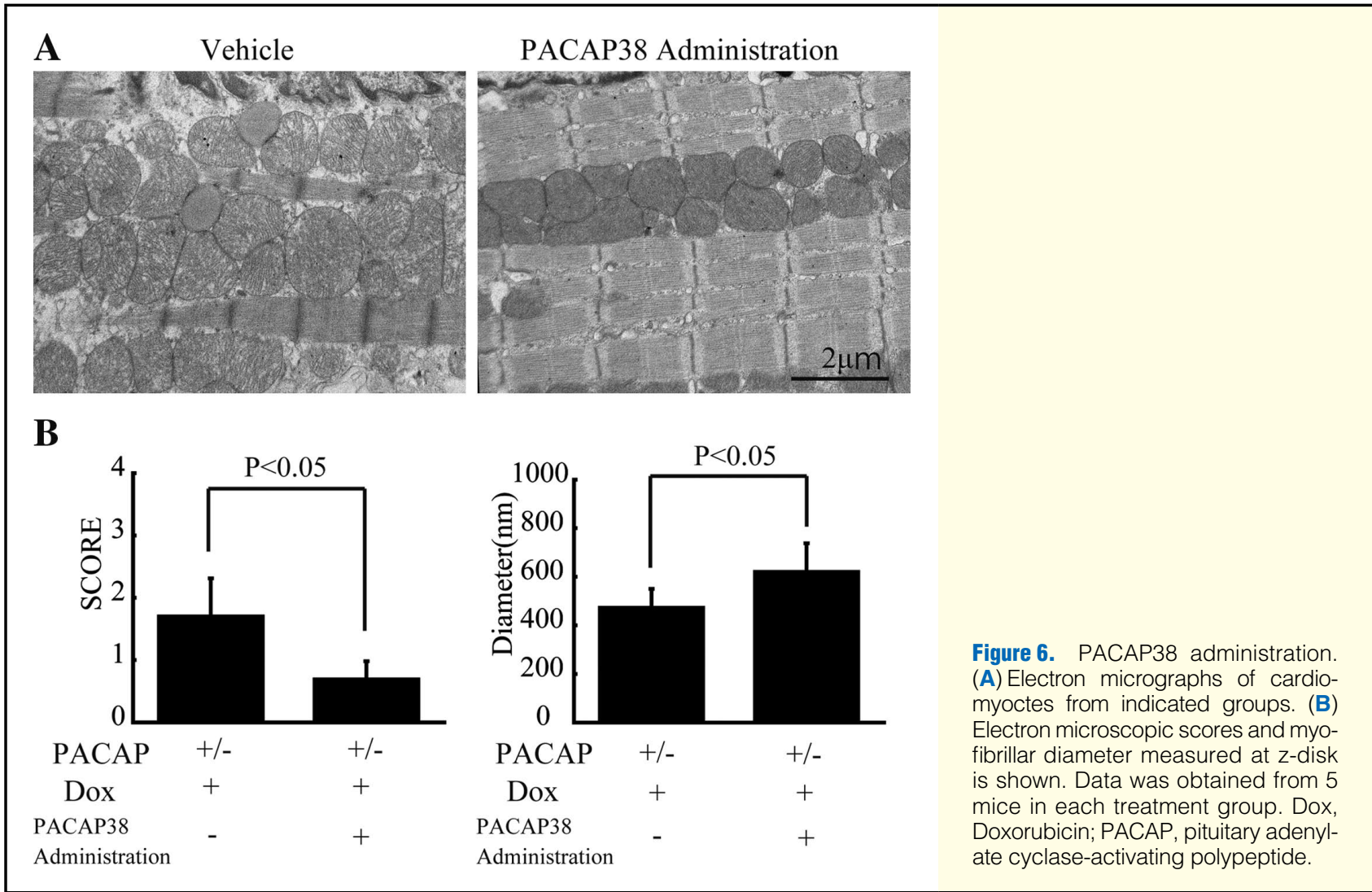

TUNEL staining. Figure 5C shows a representative picture of TUNEL staining of cardiomyoctes. TUNEL-positive cells were observed and relatively increased in the Dox-injected $\mathrm{PACAP}+/-$ mice ( $\mathrm{P}=0.16$ Student's t-test, Figure 5C).

\section{PACAP38 Administration}

Continuous subcutaneous administration of PACAP38 attenuated the cardiac damage induced by Dox injection in PACAP+/- mice, as observed by electron microscopy examination (Figure 6A). The myofibrillar diameters at z-disks were significantly longer and electron microscopic scores were significantly lower in mice from the PACAP38 injection group compared to vehicle-treated PACAP+/- mice 10 days after Dox injection (Figure 6B). Oxidative stress and survival rate did not show significant difference between these groups (data not shown).

\section{Discussion}

The present study provides the first evidence of the cardioprotective effects of endogenous PACAP in a Dox-induced cardiomyopathy model. Moreover, PACAP administration ameliorated the ultrastrucual damage induced by Dox in $\mathrm{PACAP}+/$ - mice.

Substantial evidence suggests the involvement of oxidative stress in the pathophysiology of heart failure. ${ }^{36-38}$ Similarly, the accepted mechanism of action of the cardiac toxicity of Dox is believed to be mediated by reactive oxygen species (ROS). ${ }^{19,39,40}$ It has been considered that the production of ROS in the heart by Dox occurs via redox cycling of the drug at complex I of the electron transport chain. ${ }^{39}$ Accordingly, a number of studies have tried to attenuate oxidative stress in Dox-induced cardiomyopathy. ${ }^{39-43}$ In several studies, probu- col (a lipid-lowering drug) and vitamins (A, E, and C) and $\mathrm{N}$-acetylcysteine and $\mathrm{H}_{2} \mathrm{~S}$ were used as antioxidants against ROS in Dox-induced myocardial damage, although their efficacy was limited. ${ }^{40,41,43}$ Endogenous PACAP is known to act as a protectant for cerebellar neurons against ethanol or oxidative insults. ${ }^{16,44}$ One of its neuroprotective mechanisms involves the inhibition of NADPH oxidase, which is a main ROS-producing enzyme. ${ }^{45}$ Gasz et al reported that PACAP protected cardiomyoctes against oxidative stress-induced apoptosis via suppression of the MAP kinase-dependent apoptotic pathway in vitro. ${ }^{29,30}$ In the present study, PACAP+/mice showed higher production of d-ROM and a higher percentage of 8-OHdG positive nuclei in the heart compared to WT mice (Figures 4,5A,B). These results imply that endogenous PACAP repairs or reduces myocardial and serum oxidative stress damage.

Apoptosis plays a key role in the pathogenesis of a variety of cardiovascular diseases, due to loss of terminally differentiated cardiomyocytes. ${ }^{46-49}$ One of the mechanisms of cardiac toxicity of Dox is explained by the induction of cardiomyocyte apoptosis, because the number of TUNEL positive nuclei was increased in mice with Dox-induced cardiomyopathy. ${ }^{35,40,41,50,51}$ Cardiomyocyte apoptosis in Doxinduced cardiomyopathy was shown to be inhibited by overexpression of heat shock protein 27 and by administration of an angiotensin II type 1a receptor antagonist in vivo. ${ }^{35,50}$ Ghrelin, which is a novel peptide, also protected cardiomyocytes against Dox cardiotoxicity, through anti-oxidative and anti-apoptotic mechanisms in association with TNF- $\alpha .{ }^{42}$ PACAP is similarly considered to have anti-apoptotic effects.1,16,21-24 This anti-apoptotic effect of PACAP is mediated through the MAP-kinase pathway and can account for the inhibition of caspase- 3 activation typically observed. ${ }^{16}$ 
PACAP also attenuates cultured cardiomyocyte apoptosis from oxidative stress and ischemia/re-perfusion stress, through anti-apoptotic effects. ${ }^{29-31}$ In the present study, the number of TUNEL positive nuclei increased in PACAP+/- mice after Dox injection (Figure 5C). This data indicates endogenous PACAP has anti-apoptotic effects in cardiac tissue. A further study is required to confirm the reproducibility and understanding of the mechanism.

Atrial natriuretic polypeptide (ANP) is known to be cardioprotective in various cardiovascular disease models. ${ }^{52,53}$ Sano et al reported a cardioprotective effect of PACAP on cultured rat cardiomyocytes via secretion of ANP and regulation of cardiac fibrosis. ${ }^{54}$ Although the involvement of ANP was not evaluated in the present study, the cardioprotective mechanism of endogenous PACAP might be associated with the production of ANP.

VIP, which belongs to same peptide family, has also been considered as one of the cardio-protectant coordinated with nitric oxide..$^{55}$ Thus, the VIP concentration in PACAP deficient mouse is important in this study. Girard et al reported the non-compensation of VIP in peptide/receptor gene expression in the brain of PACAP KO mice, ${ }^{56}$ but not in the heart. Although similar phenomenon is assumed in PACAP deficient mouse heart, further examination is needed.

We showed that endogenous PACAP acts as a cardiac protective agent against Dox toxicity, but did not account for the source of endogenous PACAP. PACAP-immunoreactive neuronal fibers have been identified within the cardiac plexus of guinea pigs and rats. ${ }^{6,7,11}$ Moreover, Borzsei et al reported PACAP38 is present in human plasma. ${ }^{57}$ Considering these reports, the source of endogenous PACAP present could be a neuron or derived from the plasma. Cardiomyocytes could also be the primary source, like their production of ANP, although there is no data to definitively support this concept. Furthermore, PACAP-specific (PAC1) receptor immunoreactivity and RNA have been detected in cardiac neurons and other tissues in guinea pigs and rats. ${ }^{6,8} \mathrm{PAC} 1$ receptor mRNA is also expressed in human and mouse heart.9,10 These reports imply that PACAP has a direct effect on the myocardium.

We showed that continuous administration of PACAP38 to PACAP+/- mice attenuated Dox-induced myocardial damage, suggesting that systemic administration of the exogenous PACAP38 delivered, had a protective effect on the heart (Figure 6). In a previous in vitro study, the effective dose of PACAP38 as a protective agent was indicated from 10 to $100 \mathrm{nmol} / \mathrm{L}$ for both cerebellar granule neurons and cardiomyocytes. ${ }^{1629,31}$ Accordingly, PACAP38 seems to have a protective effect on neurons and cardiomyocytes at almost the same effective dose. In the present study, we chose the dose of PACAP38 administration according to our cerebral ischemic model study previously reported, which showed the neuroprotective effects of PACAP by continuous intravenous infusion. ${ }^{22}$ The dose was based on its transportation rate from the blood to the brain across the blood-brain-barrier (BBB) of approximately $0.12 \% .{ }^{58}$ However, it seems likely that about 1,000-times higher concentration of PACAP is delivered to the heart via normal blood flow compared with in the brain, because there is no BBB in the heart. Therefore, we believe that continuous subcutaneous administration of PACAP could probably deliver a sufficient effective dose to the heart for cardio-protection. However, a significant change was detected in the ultrastracture level, but not in oxidative stress and survival in PACAP+/- Dox mice, which were administrated PACAP38. We have thought the reason that ultrastractural change of cardiomyocyte started at the early stage of injury, and electronmicroscopic examination was one of the most sensitive methods to detect the myocardium damage. ${ }^{40}$ In addition, dose and the route of PACAP38 administration were not well assessed in this study. We only tried continual subcutaneous administration of PACAP38 at a single dose of $16 \mathrm{pmol} / \mathrm{h}$. To investigate the detailed effect of PACAP, we will try to continue cardioprotective effect of PACAP in the next steps by changing dose and route of administration. Further investigations are required to understand the cardio-protective effect of PACAP by evaluating PACAP concentrations in serum during the continuous subcutaneous administration of PACAP38, and finding the best dose and route of PACAP administration.

In conclusion, the present study demonstrates for the first time a cardioprotective effect of endogenous PACAP on the failing heart. PACAP also shows significant potential as a future candidate drug for the treatment of heart failure.

\section{Acknowledgments}

This work was supported, in part, by Research on Health Sciences focusing on Drug Innovation from The Japan Health Sciences Foundation (S.S.), a Showa University Grant-in-Aid for Innovative Collaborative Research Projects (S.S.), a Special Research Grant-in-Aid for Development of Characteristic Education from the Ministry of Education, Culture, Sports, Science and Technology (T.N. and S.S.) and subsidies for ordinary expenses' of private schools from The Promotion and Mutual Aid Corporation for Private Schools of Japan. We are grateful to Fumio Hasegawa for his technical assistance.

\section{References}

1. Arimura A. Perspectives on pituitary adenylate cyclase activating polypeptide (PACAP) in the neuroendocrine, endocrine, and nervous systems. Jpn J Physiol 1998; 48: 301-331.

2. Arimura A, Shioda S. Pituitary adenylate cyclase activating polypeptide (PACAP) and its receptors: Neuroendocrine and endocrine interaction. Front Neuroendocrinol 1995; 16: 53-88.

3. Sherwood NM, Krueckl SL, McRory JE. The origin and function of the pituitary adenylate cyclase-activating polypeptide (PACAP)/ glucagon superfamily. Endocr Rev 2000; 21: 619-670.

4. Vaudry D, Gonzalez BJ, Basille M, Yon L, Fournier A, Vaudry H. Pituitary adenylate cyclase-activating polypeptide and its receptors: From structure to functions. Pharmacol Rev 2000; 52: 269-324.

5. Shioda S, Ohtaki H, Nakamachi T, Dohi K, Watanabe J, Nakajo S, et al. Pleiotropic functions of PACAP in the CNS: Neuroprotection and neurodevelopment. Ann N Y Acad Sci 2006; 1070: 550-560.

6. Braas KM, May V, Harakall SA, Hardwick JC, Parsons RL. Pituitary adenylate cyclase-activating polypeptide expression and modulation of neuronal excitability in guinea pig cardiac ganglia. J Neurosci 1998; 18: 9766-9779.

7. Calupca MA, Vizzard MA, Parsons RL. Origin of pituitary adenylate cyclase-activating polypeptide (PACAP)-immunoreactive fibers innervating guinea pig parasympathetic cardiac ganglia. J Comp Neurol 2000; 423: 26-39.

8. DeHaven WI, Cuevas J. Heterogeneity of pituitary adenylate cyclase-activating polypeptide and vasoactive intestinal polypeptide receptors in rat intrinsic cardiac neurons. Neurosci Lett 2002; 328: $45-49$.

9. Ushiyama M, Sugawara H, Inoue K, Kangawa K, Yamada K, Miyata A. Characterization of the PAC1 variants expressed in the mouse heart. Ann N Y Acad Sci 2006; 1070: 586-590.

10. Wei Y, Mojsov S. Tissue specific expression of different human receptor types for pituitary adenylate cyclase activating polypeptide and vasoactive intestinal polypeptide: Implications for their role in human physiology. J Neuroendocrinol 1996; 8: 811-817.

11. Richardson RJ, Grkovic I, Anderson CR. Immunohistochemical analysis of intracardiac ganglia of the rat heart. Cell Tissue Res 2003; 314: $337-350$.

12. Merriam LA, Barstow KL, Parsons RL. Pituitary adenylate cyclaseactivating polypeptide enhances the hyperpolarization-activated nonselective cationic conductance, Ih, in dissociated guinea pig intracardiac neurons. Regul Pept 2004; 123: 123-133.

13. Parsons RL, Rossignol TM, Calupca MA, Hardwick JC, Brass KM. PACAP peptides modulate guinea pig cardiac neuron membrane excitability and neuropeptide expression. Ann N Y Acad Sci 2000; 
921: $202-210$.

14. Ascuitto RJ, Ross-Ascuitto NT, Waddell AE, Kadowitz PJ. Contractile and coronary vascular effects of pituitary adenylate cyclase activating polypeptide in neonatal pig hearts. Cardiovasc Res 1996; 31: E153- E159.

15. Hirose M, Furukawa Y, Lakhe M, Chiba S. Regional differences in cardiac effects of pituitary adenylate cyclase-activating polypeptide27 in the isolated dog heart. Eur J Pharmacol 1998; 349: 269276.

16. Vaudry D, Pamantung TF, Basille M, Rousselle C, Fournier A, Vaudry H, et al. PACAP protects cerebellar granule neurons against oxidative stress-induced apoptosis. Eur J Neurosci 2002; 15: 1451 1460.

17. Bruch L, Bychkov R, Kastner A, Bulow T, Ried C, Gollasch M, et al. Pituitary adenylate-cyclase-activating peptides relax human coronary arteries by activating $\mathrm{K}(\mathrm{ATP})$ and $\mathrm{K}(\mathrm{Ca})$ channels in smooth muscle cells. J Vasc Res 1997; 34: 11-18.

18. Dalsgaard T, Hannibal J, Fahrenkrug J, Larsen CR, Ottesen B. VIP and PACAP display different vasodilatory effects in rabbit coronary and cerebral arteries. Regul Pept 2003; 110: 179-188.

19. Minkes RK, McMahon TJ, Hood JS, Murphy WA, Coy DH, McNamara DB, et al. Differential effects of PACAP and VIP on the pulmonary and hindquarters vascular beds of the cat. $J$ Appl Physiol 1992; 72: $1212-1217$.

20. Warren JB, Cockcroft JR, Larkin SW, Kajekar R, Macrae A, Ghatei MA, et al. Pituitary adenylate cyclase activating polypeptide is a potent vasodilator in humans. J Cardiovasc Pharmacol 1992; 20: $83-87$.

21. Dohi K, Mizushima H, Nakajo S, Ohtaki H, Matsunaga S, Aruga T, et al. Pituitary adenylate cyclase-activating polypeptide (PACAP) prevents hippocampal neurons from apoptosis by inhibiting JNK/ SAPK and p38 signal transduction pathways. Regul Pept 2002; 109: $83-88$.

22. Ohtaki H, Nakamachi T, Dohi K, Aizawa Y, Takaki A, Hodoyama $\mathrm{K}$, et al. Pituitary adenylate cyclase-activating polypeptide (PACAP) decreases ischemic neuronal cell death in association with IL-6. Proc Natl Acad Sci USA 2006; 103: 7488-7493.

23. Ohtaki H, Nakamachi T, Dohi K, Shioda S. Role of PACAP in ischemic neural death. J Mol Neurosci 2008; 36: 16-25.

24. Shioda S, Ozawa H, Dohi K, Mizushima H, Matsumoto K, Nakajo $\mathrm{S}$, et al. PACAP protects hippocampal neurons against apoptosis: Involvement of JNK/SAPK signaling pathway. Ann N Y Acad Sci 1998; 865: $111-117$.

25. Arimura A, Li M, Batuman V. Potential protective action of pituitary adenylate cyclase-activating polypeptide (PACAP38) on in vitro and in vivo models of myeloma kidney injury. Blood 2006; 107: $661-668$.

26. Li M, Maderdrut JL, Lertora JJ, Arimura A, Batuman V. Renoprotection by pituitary adenylate cyclase-activating polypeptide in multiple myeloma and other kidney diseases. Regul Pept 2008; 145: $24-32$.

27. Sekiya K, Nagasaki H, Ozaki N, Suzuki A, Miura Y, Oiso Y. Pituitary adenylate cyclase-activating polypeptide prevents cytokineinduced cytotoxicity via inhibition of inducible nitric oxide synthase expression in beta TC cells. Biochem Biophys Res Commun 2000; 278: $211-216$

28. Winzell MS, Ahren B. Role of VIP and PACAP in islet function. Peptides 2007; 28: 1805-1813.

29. Gasz B, Racz B, Roth E, Borsiczky B, Ferencz A, Tamas A, et al. Pituitary adenylate cyclase activating polypeptide protects cardiomyocytes against oxidative stress-induced apoptosis. Peptides 2006; 27: 87-94.

30. Gasz B, Racz B, Roth E, Borsiczky B, Tamas A, Boronkai A, et al. PACAP inhibits oxidative stress-induced activation of MAP kinasedependent apoptotic pathway in cultured cardiomyocytes. Ann NY Acad Sci 2006; 1070: $293-297$.

31. Racz B, Gasz B, Gallyas F Jr, Kiss P, Tamas A, Szanto Z, et al. PKA-Bad-14-3-3 and Akt-Bad-14-3-3 signaling pathways are involved in the protective effects of PACAP against ischemia/reperfusion-induced cardiomyocyte apoptosis. Regul Pept 2008; 145: $105-115$

32. Hashimoto H, Shintani N, Tanaka K, Mori W, Hirose M, Matsuda $\mathrm{T}$, et al. Altered psychomotor behaviors in mice lacking pituitary adenylate cyclase-activating polypeptide (PACAP). Proc Natl Acad Sci USA 2001; 98: 13355-13360.

33. Dohi K, Satoh K, Nakamachi T, Yofu S, Hiratsuka K, Nakamura S, et al. Does edaravone (MCI-186) act as an antioxidant and a neuroprotector in experimental traumatic brain injury? Antioxid Redox Signal 2007; 9: 281 - 287
34. Rahman A, More N, Schein PS. Doxorubicin-induced chronic cardiotoxicity and its protection by liposomal administration. Cancer Res 1982; 42: 1817-1825.

35. Toko H, Oka T, Zou Y, Sakamoto M, Mizukami M, Sano M, et al. Angiotensin II type 1a receptor mediates doxorubicin-induced cardiomyopathy. Hypertens Res 2002; 25: 597-603.

36. Seddon M, Looi YH, Shah AM. Oxidative stress and redox signalling in cardiac hypertrophy and heart failure. Heart 2007; 93: $903-$ 907.

37. Tsutsui H, Kinugawa S, Matsushima S. Mitochondrial oxidative stress and dysfunction in myocardial remodelling. Cardiovasc Res 2009; 81: 449-456.

38. Tsutsui H, Kinugawa S, Matsushima S. Oxidative stress and mitochondrial DNA damage in heart failure. Circ J 2008; 72(Suppl A): A-31-A-37.

39. Berthiaume JM, Wallace KB. Adriamycin-induced oxidative mitochondrial cardiotoxicity. Cell Biol Toxicol 2007; 23: 15-25.

40. Takemura G, Fujiwara H. Doxorubicin-induced cardiomyopathy from the cardiotoxic mechanisms to management. Prog Cardiovasc Dis 2007; 49: 330-352.

41. Minotti G, Menna P, Salvatorelli E, Cairo G, Gianni L. Anthracyclines: Molecular advances and pharmacologic developments in antitumor activity and cardiotoxicity. Pharmacol Rev 2004; 56: $185-229$.

42. Xu Z, Lin S, Wu W, Tan H, Wang Z, Cheng C, et al. Ghrelin prevents doxorubicin-induced cardiotoxicity through TNF-alpha/ NF-kappaB pathways and mitochondrial protective mechanisms. Toxicology 2008; 247: 133-138.

43. Su YW, Liang C, Jin HF, Tang XY, Han W, Chai LJ, et al. Hydrogen sulfide regulates cardiac function and structure in adriamycininduced cardiomyopathy. Circ J 2009; 73: 741-749.

44. Vaudry D, Hamelink C, Damadzic R, Eskay RL, Gonzalez B, Eiden LE. Endogenous PACAP acts as a stress response peptide to protect cerebellar neurons from ethanol or oxidative insult. Peptides 2005; 26: $2518-2524$.

45. Yang S, Yang J, Yang Z, Chen P, Fraser A, Zhang W, et al. Pituitary adenylate cyclase-activating polypeptide (PACAP) 38 and PACAP4-6 are neuroprotective through inhibition of NADPH oxidase: Potent regulators of microglia-mediated oxidative stress. J Pharmacol Exp Ther 2006; 319: 595-603.

46. Clarke M, Bennett M, Littlewood T. Cell death in the cardiovascular system. Heart 2007; 93: 659-664.

47. Lee Y, Gustafsson AB. Role of apoptosis in cardiovascular disease. Apoptosis 2009; 14: 536-548.

48. van Empel VP, Bertrand AT, Hofstra L, Crijns HJ, Doevendans PA, De Windt LJ. Myocyte apoptosis in heart failure. Cardiovasc Res 2005; 67: 21-29.

49. Kumar D, Lou H, Singal PK. Oxidative stress and apoptosis in heart dysfunction. Herz 2002; 27: 662-668.

50. Liu L, Zhang X, Qian B, Min X, Gao X, Li C, et al. Over-expression of heat shock protein 27 attenuates doxorubicin-induced cardiac dysfunction in mice. Eur J Heart Fail 2007; 9: 762-769.

51. Arola OJ, Saraste A, Pulkki K, Kallajoki M, Parvinen M, VoipioPulkki LM. Acute doxorubicin cardiotoxicity involves cardiomyocyte apoptosis. Cancer Res 2000; 60: 1789-1792.

52. Kitakaze M, Asakura M, Kim J, Shintani Y, Asanuma H, Hamasaki $\mathrm{T}$, et al. Human atrial natriuretic peptide and nicorandil as adjuncts to reperfusion treatment for acute myocardial infarction (J-WIND): Two randomised trials. Lancet 2007; 370: 1483-1493.

53. Nishikimi T, Maeda N, Matsuoka H. The role of natriuretic peptides in cardioprotection. Cardiovasc Res 2006; 69: 318-328.

54. Sano H, Miyata A, Horio T, Nishikimi T, Matsuo H, Kangawa K. The effect of pituitary adenylate cyclase activating polypeptide on cultured rat cardiocytes as a cardioprotective factor. Regul Pept 2002; 109: $107-113$.

55. Das DK, Kalfin R, Maulik N, Engelman RM. Coordinated role of vasoactive intestinal peptide and nitric oxide in cardioprotection. Ann NY Acad Sci 1998; 865: 297-308.

56. Girard BA, Lelievre V, Braas KM, Razinia T, Vizzard MA, Ioffe $\mathrm{Y}$, et al. Noncompensation in peptide/receptor gene expression and distinct behavioral phenotypes in VIP- and PACAP-deficient mice. J Neurochem 2006; 99: 499-513.

57. Borzsei R, Mark L, Tamas A, Bagoly T, Bay C, Csanaky K, et al. Presence of pituitary adenylate cyclase activating polypeptide-38 in human plasma and milk. Eur J Endocrinol 2009; 160: 561-565.

58. Banks WA, Kastin AJ, Komaki G, Arimura A. Passage of pituitary adenylate cyclase activating polypeptide1-27 and pituitary adenylate cyclase activating polypeptide1-38 across the blood-brain barrier. J Pharmacol Exp Ther 1993; 267: 690-696. 